\title{
Maluco, louco, pirado: as dificuldades de resposta no questionário do ALiB para a lexia doido e o papel do inquiridor
}

\author{
Maluco, loco, pirado: las dificultades de respuesta en el \\ cuestionario del ALIB para la lexia loco y el papel del \\ inquiridor
}

\section{Barmy, crazy, mad: how difficulty was to answer the ALIB questionnaire regarding the lexicon for crazy and the inquirer's role}

\author{
Vanessa Lini Dalto ${ }^{1}$
}

\begin{abstract}
RESUMO: A Geolinguística brasileira tem alcançado inúmeros avanços nas últimas décadas. Entre as conquistas desta área destaca-se o Projeto ALiB - Atlas linguístico do Brasil (CARDOSO et al, 2014), obra que descreve a realidade linguística do país. Baseando-se neste grandioso trabalho, o presente estudo pretende analisar entrevistas do Projeto ALIB, no que tange à Região Sudeste do país (São Paulo, Rio de Janeiro, Vitória e Belo Horizonte), quanto às dificuldades enfrentadas pelo inquiridor ao aplicar o questionário fonético-fonológico (QFF). Para tanto, selecionaram-se 32 entrevistas, referentes à questão de número 138 , que procura investigar as variações fonéticas para a lexia "doido". Por se tratar de uma questão que apresenta dificuldade na obtenção da resposta, busca-se com a análise do corpus, observar o papel do inquiridor na recolha de dados completos e adequados para os fins almejados.
\end{abstract}

PALAVRAS-CHAVE: Atlas linguístico. Questionário. Inquiridor.

RESUMEN: La Geolingüística brasileña ha alcanzado innumerables avances en las últimas décadas. Entre las conquistas de esta área se destaca el Proyecto ALIB - Atlas lingüístico de Brasil (CARDOSO et al, 2014), obra que describe la realidad lingüística del país. En el presente estudio se pretende analizar entrevistas del Proyecto ALIB, en lo que se refiere a la Región Sudeste del país (São Paulo, Río de Janeiro, Vitória y Belo Horizonte), en cuanto a las dificultades enfrentadas por el inquiridor al aplicar el cuestionario fonético -fonológico (QFF). Para ello, se seleccionaron 32 entrevistas,

1 Mestre em Estudos da Linguagem pelo Programa de pós-graduação em Estudos da Linguagem e Doutoranda pelo mesmo programa. Atua como professora de Língua Portuguesa e séries iniciais. Contato: vanessa.lini@hotmail.com. 
referentes a la cuestión del número 138, que busca investigar las variaciones fonéticas para la lexia "loco". Por tratarse de una cuestión que presenta dificultad en la obtención de la respuesta, se busca con el análisis del corpus, observar el papel del inquiridor en la recogida de datos completos y adecuados para los fines anhelados.

PALABRAS CLAVE: Atlas lingüístico. Cuestionario. Inquiridor.

ABSTRACT: Brazilian Geolinguistics has reached many advances in the last decades. Among the achievements of this area is the Project ALiB - Linguistic Atlas of Brazil (CARDOSO et al, 2014), a work that describes the linguistic reality of the country. Based on this great work, the present study intends to analyze interviews of the ALiB Project, regarding the Southeast Region of the country (São Paulo, Rio de Janeiro, Vitória and Belo Horizonte), regarding the difficulties faced by the inquirer when applying the phonetic-phonological questionnaire (QFF). In order to do so, we selected 32 interviews, referring to question number 138, which seeks to investigate the phonetic variations for lexicon for "crazy". Because it is an issue that presents difficulties in obtaining the answer, it is sought through the analysis of the corpus, to observe the role of the inquirer in the collection of complete and adequate data for the desired ends.

KEYWORDS: Language Atlas. Quiz. Inquirer.

\section{Introdução}

É fato que a Língua Portuguesa, assim como qualquer língua, é um instrumento de comunicação heterogêneo. Modifica-se no tempo e no espaço e apresenta variação quanto a questões de ordem sociocultural, histórica, regional, situacional, entre outras.

Assim, estudos geolinguísticos, que englobam a diversidade linguística de uma língua ou dialeto, vêm ganhando destaque no Brasil com a produção de atlas estaduais e regionais e a conquista do Atlas Linguístico do Brasil-ALiB.

Os atlas geralmente são compostos de dados coletados em forma de entrevistas em que um informante com perfil pré-determinado responde a questões cujas respostas são analisadas quanto aos fenômenos fonéticos, lexicais, semânticos e morfossintáticos, de acordo com objetivos anteriormente estabelecidos. 
Nessa perspectiva, a relação inquiridor e informante é de suma importância na busca por dados confiáveis, completos e que expressem a verdadeira realidade linguística de determinada localidade.

Diante de tal constatação, a presente pesquisa pretende analisar o papel do inquiridor no trabalho de recolha dos dados e sua função mediadora nas questões em que os informantes apresentam dificuldades de alcançar a resposta prevista pelo questionário. Para tanto, selecionou-se a questão 138 do questionário fonético-fonológico, (QFF), do Projeto ALiB, que apresenta tal problemática, com o intuito de analisar o nível de êxito das respostas e as estratégias utilizadas pelo inquiridor na intervenção para a realização do item lexical esperado. Espera-se que os resultados deste estudo ressaltem a importância do inquiridor no processo de levantamento de dados de um atlas, além de demonstrar parte das dificuldades enfrentadas por pesquisadores geolinguistas.

\section{Atlas linguístico}

Pode-se considerar que produzir e concretizar um projeto de atlas linguístico não se configura uma fácil tarefa, mas sim o enfrentamento de um trabalho árduo que exige acima de tudo perseverança, paciência e persistência. Fatos como ampla extensão territorial, disponibilidade de tempo para as entrevistas e falta de recursos financeiros, são algumas das dificuldades enfrentadas por pesquisadores desta área. Tais barreiras podem explicar o fato de algumas localidades não possuírem atlas linguísticos nacionais, como é o caso de Portugal e Espanha, em que os estudos dialetológicos se concentram em atlas regionais.

Com o intuito de investigar a variação na oralidade existente em diferentes níveis, os atlas são desenvolvidos pelo método da geolinguística que, conforme Coseriu, (1987) define-se como: 
Um método dialectológico e comparativo [...] que pressupõe o registro em mapas especiais de um número relativamente elevado de formas linguísticas (fônicas, lexicais ou gramaticais) comprovadas mediante pesquisa direta e unitária numa rede de pontos de determinado território, ou que, pelo menos, tem em conta a distribuição das formas no espaço geográfico correspondente à língua, às línguas, aos dialetos ou aos falares estudados. (COSERIU, 1987, p. 79)

Deste modo, os atlas são uma forma de documentação da diversidade da língua constante em determinada região permitindo também a verificação do surgimento de novas formas e a conservação de formas antigas. Coseriu (1987, p. 93) comenta que um atlas linguístico constitui um valioso inventário de formas além de apresentar clareza e evidência imediata dos fenômenos levantados nos pontos estudados.

No Brasil, após uma empreitada de 20 anos, concretiza-se o Atlas Linguístico do Brasil-ALiB, um atlas geral brasileiro que descreve diferentes formas da língua portuguesa praticada no país.

\section{ALiB- Atlas linguístico do Brasil}

O Projeto ALiB teve início em 1996, quando foi criado um Comitê Nacional responsável por definir e traçar as metas desse amplo empreendimento linguístico.

$\mathrm{Na}$ busca de dados que permitissem uma descrição da realidade linguística brasileira, este projeto interinstitucional começa a ganhar forma a partir daquele ano, envolvendo pesquisadores de várias instituições do Brasil sob a presidência da Dra. Suzana Alice Marcelino Cardoso da UFBA que, em 1998, já o apresentava da seguinte forma:

O atlas lingüístico do Brasil, ao tempo em que prioriza a identificação espacial dos fenômenos, se propõe não só manter sob controle certas variáveis sociais dos informantes, como também fornecer comentários e estudos interpretativos que acompanharão as cartas e, ainda tentar estabelecer, via Internet, um sistema de consulta à distância que faculte ao leitor o conhecimento de formas ou usos linguageiros e também Ihe dê a possibilidade de ouvir, de viva voz, as realizações 
daquela área cartografada e selecionada para audição. Do ponto de vista da orientação teórica, pretende ser o ALIB um atlas de terceira geração, reunindo, assim, às informações linguísticas cartografadas, estudos e comentários às cartas e oferecendo as facilidades de acesso aos dados vivos por meio do que os franceses identificam com um atlas informatisé et parlant. (CARDOSO, 1998, p. 13)

Para a realização do projeto estabeleceu-se uma rede de pontos linguísticos de 250 localidades brasileiras e a seleção de 1100 informantes, escolhidos quanto ao sexo, escolaridade e faixa etária. Participaram das entrevistas mulheres e homens alfabetizados, com no máximo o Ensino Fundamental completo e pertencentes a duas faixas etárias: 18 a 30 anos e 50 a 65 anos. Nas capitais foram acrescidos mais quatro informantes do mesmo perfil anterior, com exceção da escolaridade que abrange também o nível universitário.

Parte dos resultados desta ampla pesquisa já está disponível em formato de livro desde 2014, ano em que o Projeto ALiB foi publicado pela Editora da Universidade Estadual de Londrina. A edição abrange os dados das 25 capitais brasileiras e apresenta-se em dois volumes: o primeiro, que trata da estrutura do Atlas e o segundo, que apresenta as 159 cartas linguísticas propriamente ditas, que exploram a variação nos níveis fonético-fonológico, semântico-lexical e morfossintático.

O ALiB é considerado um atlas moderno, insere-se na categoria de atlas de $2^{\mathrm{a}}$ geração, pois, fornece além das cartas linguísticas estudos interpretativos sobre os aspectos cartografados. Outro dado positivo do Atlas brasileiro se refere à metodologia embasada na Dialetologia pluridimensional, parâmetro que, segundo Cardoso e Mota (2006), se caracteriza pelo interesse em diferentes tipos de variação:

$\mathrm{Na}$ geolinguística pluridimensional contemporânea, soma-se ao parâmetro diatópico, prioritário em trabalhos dessa natureza, o interesse por outros tipos de variação, como a diagenérica, adiastrática, a diageracional, entre outras. E, para atender a tal exigência, incluem-se informantes dos dois gêneros, de diferentes 
Maluco, louco, pirado: as dificuldades de resposta no questionário do ALiB para a lexia doido e o papel do inquiridor

estratos sociais e de mais de uma faixa etária[...] (CARDOSO; MOTA, 2006, p. 22).

Tal projeto se destaca por seu comprometimento e fidelidade de pesquisa que, sob a ótica da Dialetologia Pluridimensional, foi pensado para alcançar uniformidade metodológica quanto aos objetivos, instrumentos de coleta de dados, metas e critérios conforme exposto nos próximos itens.

\section{Objetivos do ALiB}

De acordo com o Documentos 4 (CORDOSO, 2013), o Projeto ALiB destaca-se entre os outros trabalhos geolinguísticos por considerar, além da variação diatópica, outros fatores de natureza social como o sexo, a idade e o grau de escolaridade. Desta forma, apresenta os seguintes objetivos:

1. Descrever a realidade linguística do Brasil, no que tange à língua portuguesa, com enfoque prioritário na identificação das diferenças diatópicas (fônicas, morfossintáticas e léxico-semânticas) consideradas na perspectiva da Geolinguística pluridimensional.

2. Oferecer aos estudiosos da língua portuguesa (linguistas, lexicólogos, etimólogos, filólogos, etc.), aos pesquisadores de áreas afins (história, antropologia, sociologia, etc.) e aos pedagogos (gramáticos, autores de livros-texto, professores) subsídios para o aprimoramento do ensino/aprendizagem e para uma melhor interpretação do caráter multidialetal do Brasil.

3. Estabelecer isoglossas com vistas a traçar a divisão dialetal do Brasil, tornando evidentes as diferenças regionais através de resultados cartografados em mapas linguísticos e realizar estudos interpretativos de fenômenos considerados.

4. Examinar os dados coletados na perspectiva de sua interface com outros ramos do conhecimento-história, sociologia, antropologia, etc. - de modo a poder contribuir para fundamentar e definir posições teóricas sobre a natureza da implantação e desenvolvimento da língua portuguesa no Brasil.

5. Oferecer aos interessados nos estudos linguísticos um considerável volume de dados que permita aos lexicógrafos aprimorarem os dicionários, ampliando o campo de informações; aos gramáticos atualizarem as informações com base na realidade documentada pela pesquisa empírica; aos autores de livros didáticos adequarem a sua produção à realidade cultural de cada região; aos professores aprofundar o conhecimento da realidade linguística, 
refletindo sobre as variantes de que se reveste a língua portuguesa no Brasil e, consequentemente, encontrando meios de, sem desprestigiar os seus dialetos de origem, levar os estudantes ao domínio de uma variante tida como culta.

6. Contribuir para o entendimento da língua portuguesa no Brasil como instrumento social de comunicação diversificado, possuidor de várias normas de uso, mas dotado de uma unidade sistêmica. (CARDOSO, 2013, p. 32-33.)

Para tanto, a definição dos instrumentos metodológicos se configura como parte essencial para a concretização dos objetivos.

\section{Instrumentos metodológicos: Questionário linguístico}

O projeto ALiB utilizou, como parte de seus instrumentos metodológicos, questionários linguísticos que foram elaborados com direcionamento para os aspectos fonético-fonológico, semântico- lexical e morfossintático. Sobre a formulação de questionários linguísticos, Aragão (2003) salienta:

Para se formular um questionário é necessário verificar o conteúdo das questões e sua clareza, direcionando-as para que atinja os objetivos esperados em relação ao levantamento de dados a que se propõe. O questionário deve ser o mais objetivo possível, descrevendo as características e medindo determinadas variáveis de um grupo social (ARAGÃO, 2003, p. 63).

Para garantir a eficiência da recolha de dados do $A$ LiB, as questões foram aprimoradas conforme resultados de aplicações experimentais até chegar a uma versão final do questionário publicada em 2001e que apresenta seis tipos de questionários: o questionário fonético-fonológico (QFF), com 159 perguntas, o morfossintático (QMS), com 49 perguntas e o questionário semântico-lexical (QSL), com 202 questões, além de 04 questões de pragmática, temas para discurso dirigidos, 06 perguntas metalinguísticas e um texto para leitura. 
Conforme o Documentos 4 (CARDOSO, 2013), o QFF objetiva recolher dados sobre a variação fonética, além de questões de prosódia, relativas à natureza das frases interrogativas, afirmativas e imperativas enquanto 0 morfossintático (QMS) procura apurar as variantes diatópicas, como a utilização ou não do artigo antes de nomes próprios e o uso de tu ou você como segunda pessoa, além da flexão de gênero e número e concordância. Já o questionário semântico-lexical (QSL) visa à obtenção de designações diferentes para o mesmo conceito, objeto, coisa ou acontecimento, cobrindo 14 áreas semânticas - acidentes geográficos, fenômenos atmosféricos, astros e tempo, atividades agropastoris, fauna, corpo humano, ciclos da vida, convívio e comportamento social, religião e crenças, jogos e diversões infantis, habitação, alimentação e cozinha, vestuário e acessórios e vida urbana. Ressalta-se que as questões foram pensadas para abranger a totalidade do território nacional não tendo sido contemplados aspectos particulares e regionais, o que as torna adequadas a todas as regiões.

Desta forma, os questionários apresentam-se como ferramenta principal na coleta de dados de um atlas, portanto, destaca-se a importância de quem irá manipular essa ferramenta, ou seja, o inquiridor.

\section{O papel do inquiridor ${ }^{1}$}

Em uma pesquisa dialetológica, a recolha dos dados no campo compõe uma das partes essenciais desse tipo de trabalho. Assim, cabe ao pesquisador e sua equipe o deslocamento a diferentes localidades, o contato direto com os informantes e a aplicação dos questionários destinados às entrevistas.

De acordo com Mouton (1996, p. 65), o pesquisador de campo é o investigador preparado para elegir informante, preguntarle adecuadamente el

\footnotetext{
${ }^{1}$ Os termos inquiridor/pesquisador estão de acordo com a denominação utilizada pelo Projeto ALIB.
} 
cuestionario y transcribir sus respuestas, ou seja, o inquiridor, por ela denominado encuestador deve ser uma pessoa preparada para tal.

Assim, o inquiridor, seja ele o próprio pesquisador ou outro integrante da equipe de pesquisa, precisa estar munido de estratégias para alcançar por meio dos informantes os objetivos traçados para este propósito. Ferreira e Cardoso (1994, p. 33) enumera quatro questões de fundamental importância para a preparação de tal indivíduo: "1) Discussão conjunta do questionário que se vai aplicar; 2) audição de inquéritos de diferentes tipos; 3) Domínio de um sistema de transcrição fonética e 4) a presença do inquiridor durante o inquérito".

Os quatro pontos elencados por Ferreira refletem sobre a importância de o inquiridor conhecer e ter domínio do questionário a ser aplicado para ter consciência das dificuldades que irá encontrar e planejamento dos métodos que podem ser usados para alcançar a resposta desejada. A autora evidencia, também, a relevância de o inquiridor possuir formação e conhecimento fonético, pois, em caso de uma falha do equipamento de gravação a documentação dos dados manualmente é uma garantia de preservação das informações da entrevista.

Interessante comentar a colocação da autora referente ao item quatro que trata da presença do inquiridor durante o inquérito. Segundo a autora, a aplicação de questionários por correspondência, ou seja, sem o contato direto informante-documentador, pode inviabilizar os dados já que podem ficar questões sem respostas ou mal interpretadas que não podem ser explicadas ou retomadas pelo inquiridor. Desta forma, entrevistas presenciais garantem maior validade e confiabilidade dos dados, que constituem o eixo central de uma pesquisa geolinguística.

\section{Os dados}

O corpus desta pesquisa constitui-se de parte do banco de dados do projeto $\mathrm{ALiB}$ no que se refere a entrevistas de 32 informantes das capitais da 
região Sudeste do Brasil: São Paulo, Rio de Janeiro, Vitória e Belo Horizonte. Em cada capital foram entrevistadas oito pessoas seguindo os critérios de faixa etária, escolaridade e sexo estabelecidos pelo ALIB.

Para a presente pesquisa, selecionou-se a pergunta 138 do questionário fonético-fonológico que tem o seguinte enunciado: Que nome se dá a uma pessoa que às vezes fica furiosa, agressiva, precisa até ser internada no hospício? Tal pergunta espera do informante a resposta doido com o intuito de verificar as variações fonéticas para esta lexia: ['dojdu], ['dojdzu] e [dodzu].

Visto que nem sempre a resposta do informante condiz com a resposta esperada pelo pesquisador, analisamos as ocorrências das respostas para a pergunta 138 do QFF da região Sudeste do Brasil da seguinte forma: (i) no de respostas imediatas; (ii) $n^{\circ}$ de respostas positivas, obtidas após tentativas e mediação do inquiridor e (iii) $n^{0}$ de respostas alternativas, que não atendem 0 objetivo do questionário. De posse das respostas, analisou-se o papel do inquiridor na obtenção da resposta adequada à questão.

O gráfico 1 mostra as ocorrências das respostas por região:

Gráfico 1 - Referente às respostas para a questão 138 por região.

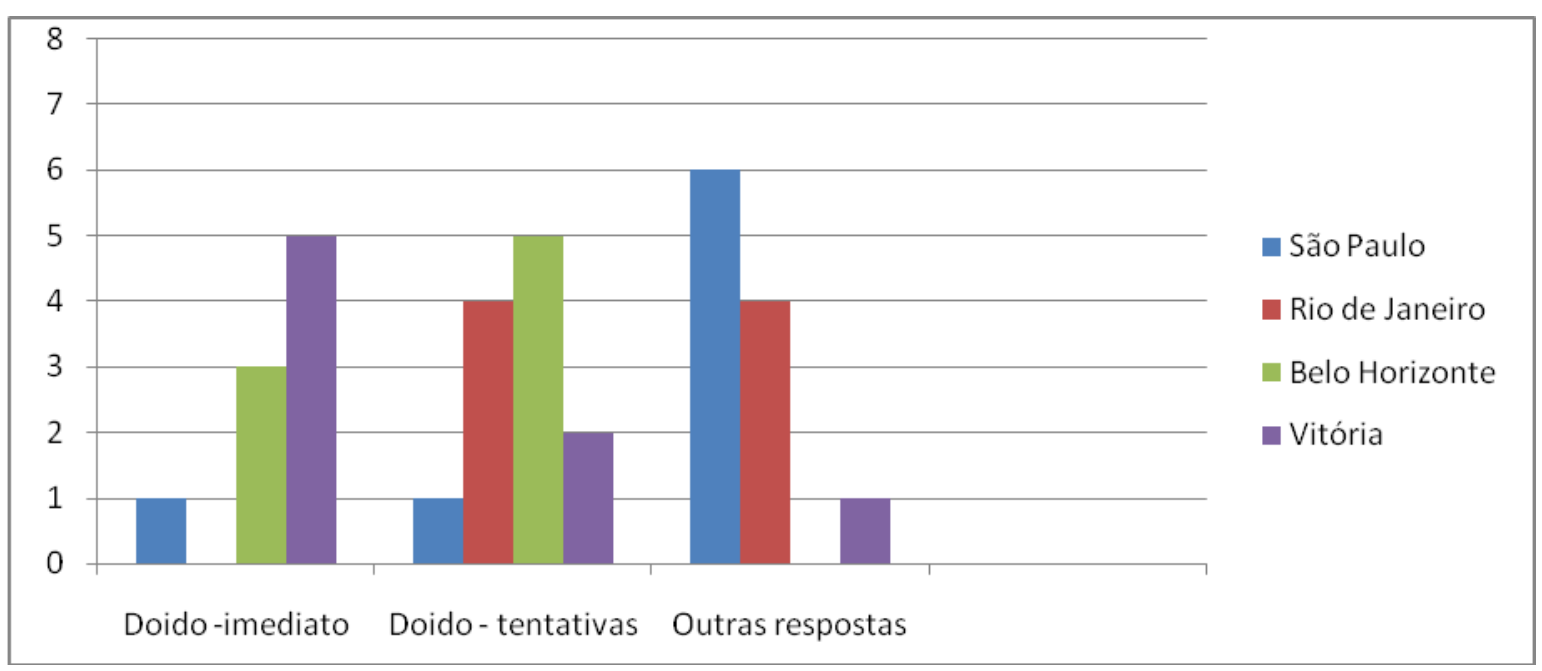

Fonte: Elaboração da autora mediante dados do banco do ALiB. 
Conforme o gráfico 1 é possível observar que a resposta doido não se realiza em todas as entrevistas e que, em muitos casos, apenas aparece após a citação de outros itens lexicais correspondentes como: louco, maluco, pirado, desequilibrado, nervoso, perturbado, descontrolado, etc. Os dados da capital São Saulo divergem acentuadamente dos das outras capitais, pois, apenas um dos oito informantes respondeu doido, enquanto os demais utilizaram outras lexias, com preferência para o vocábulo louco. Verifica-se também que, com exceção de Vitória, a realização da resposta doido não ocorre com maior frequência como $1^{\text {a }}$ opção de resposta, mas sim, após artifícios utilizados pelo entrevistador para conduzir o entrevistado a chegar ao foco da questão.

O Gráfico 2 mostra, por capital, o número de tentativas para a obtenção da forma esperada: 
Maluco, louco, pirado: as dificuldades de resposta no questionário do ALiB para a lexia doido e o papel do inquiridor

Gráfico 2 - Referente ao número de tentativas do inquiridor para alcançar a resposta desejada.

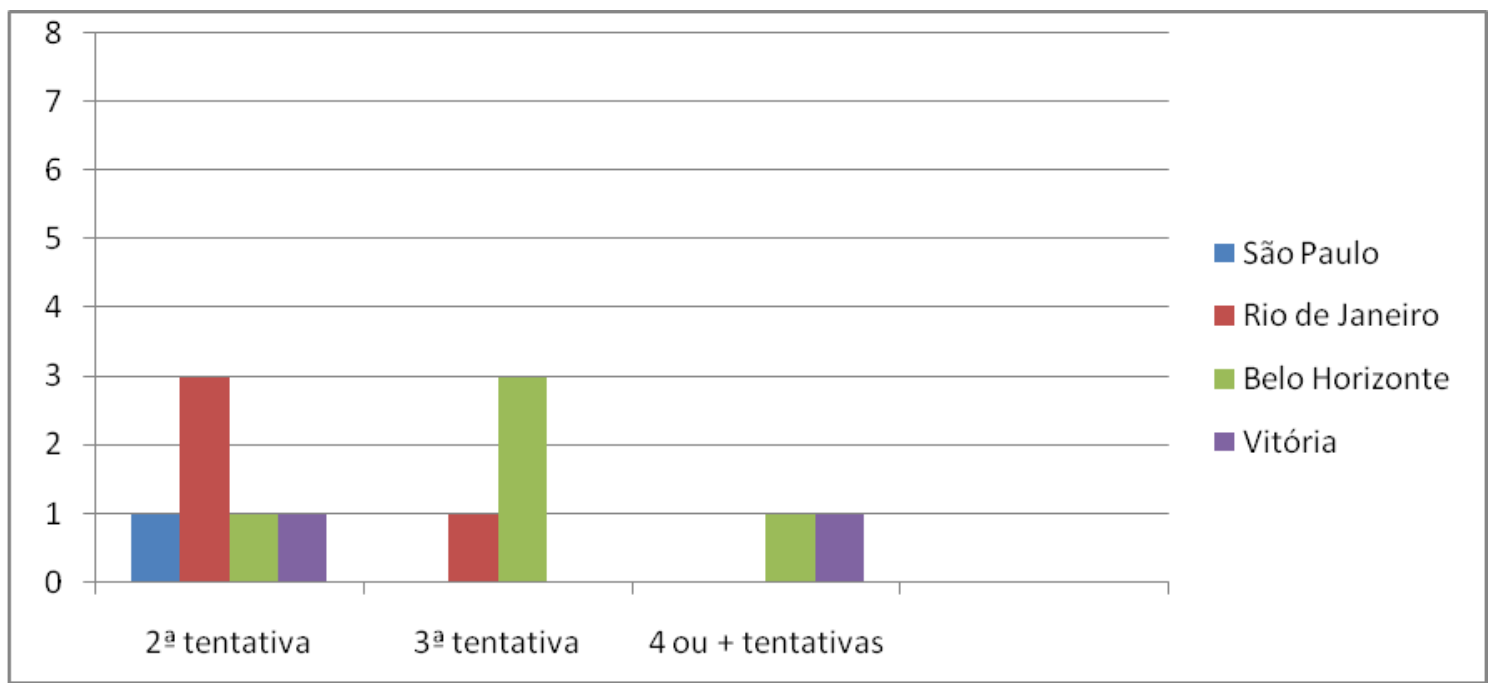

Fonte: Elaboração da autora mediante dados do banco do ALiB.

Verifica-se que houve casos que exigiram até quatro ou mais reformulações de pergunta ou explicações do entrevistador para o sucesso da resposta, o que mostra a dificuldade do entrevistador na busca do item lexical de determinada questão. Ressalta-se, também, que as estratégias utilizadas pelo inquiridor apresentam-se de maneira sutil, a fim de tornar a entrevista uma conversa agradável, e mantendo sempre o cuidado de não constranger ou esgotar o informante, já que os questionários são extensos e contam com a boa vontade de quem se propõe a participar.

As entrevistas analisadas não foram feitas por apenas um inquiridor, portanto observam-se diferentes estratégias, das mais simples às mais complexas, tais como:

- O que mais?

- Você conhece por outro nome? / Tem outro nome?

- O povo fala outros nomes? / Você conhece outra palavra sinônima disso?

- Quando a pessoa fica agressiva, nervosa a gente diz que ela ficou....?

- E quando ela precisa até ser internada a gente diz que ela está...? 
- Quando você está com muita vontade de comer alguma coisa diz que está ... de vontade.

- E se você está com muita fome. Diz que está... de fome.

- Se alguém mandar você pular de pára-quedas, você diz: - Eu não, não sou... ou diz:

-Vai você porque você é...

Embora o entrevistador tenha se esforçado, lançando mão de vários recursos para ter sucesso com esta questão, em alguns casos, a resposta não foi alcançada. É significativo o número de insucessos, pois, dos 32 informantes analisados, 11 não chegaram à resposta doido. Destes, nove receberam mediação do inquiridor e, mesmo assim, o objetivo não foi alcançado. Para comprovar essa dificuldade, ilustra-se a transcrição grafemática de dois destes casos:

-Informante 06 - Capital São Paulo:

INQ.: Que nome se dá a uma pessoa que às vezes fica furiosa, agressiva, precisa até ser internada no hospício?

INF.: Nervosa?

INQ:: As vezes até tem que internar?

INF.: Loca?

INQ.: Que mais?

INF.: Rebeldi, irritada, stressada?

INQ.: Quando você tá morrendo de vontade de comer um doce, você diz que está ... de vontade.

INF.: Com vontade.

INQ.: Mas tá com muita vontade fala que tá?

INF.: Com vontade.

-Informante 07 - Vitória - ES:

INQ.: Que nome se dá a uma pessoa que às vezes fica furiosa, agressiva, precisa até ser internada no hospício?

INF.: Mal humorada?

INQ.: Ela precisa até ser internada?

INF.: Loca?

INQ.: Além de loca tem outro nome? 
INF.: Disiquilibrada?

INQ.: Se o Senhor convidasse a Giovana para saltar de pára-quedas ela ia dizer assim: "Eu não, vai você porque eu não sou... ?

INF.: Loca?

INQ.: Ou então?

INF.: Maluca?

Observa-se, nos trechos, que os informantes acreditam ter esgotado seu repertório de parassinônimos quando repetem respostas anteriores. Em ambos os casos o inquiridor faz cinco tentativas sem êxito e passa para a pergunta seguinte, acreditando que a sua insistência em apenas uma questão poderia comprometer a resposta das questões seguintes, e que o melhor caminho seria prosseguir com o questionário como ele o fez. Não houve sucesso, mas o pesquisador cumpriu seu papel.

Em alguns casos de insucesso o pesquisador ainda utiliza o recurso de retomada ao final do questionário, em que novamente insiste e investe em questionamentos que possam trazer a lexia desejada. Um exemplo é o caso do informante 05 da capital São Paulo:

Informante 05 - entrevista inicial:

INQ.: Que nome se dá a uma pessoa que às vezes fica furiosa, agressiva, precisa até ser internada no hospício?

INF.: Loco.

INQ.: Mais algum outro nome fora o louco?

INF.: Descontrolada, sei lá...

Informante 05 - Retomada

INQ.: Voltamos né, ficou aqui...

INQ.: Que nome se dá a uma pessoa que às vezes fica furiosa, agressiva, precisa até ser internada no hospício? Você já me falou louca, mas eu quero uma outra palavra.

INF.: Furiosa...esquiso... não... Humhum... furiosa, agressiva?

INQ.: Por exemplo, ah... qual doce de que você mais gosta ou prato de que você mais gosta?

INF.:Fejoada. 
INQ.: Isso, então você fica assim, você viajou para Austrália não comeu feijoada aí quando chega fala mãe faz uma feijoada por que eu tô... o que de vontade?

INF.:Morrendo de vontade, tô...?

INQ.: O que de vontade?

INF.:Surtando... não sei...

INQ.: Tá por aí, eh... tá no surto tá na...

INF.:Passando mal?

INQ.: Não, eu tô louco de vontade, tô o que de vontade?

INF.:Loco, morrendo?

INQ.: Essa palavrinha é duro de eu tirar, todo mundo fala tudo, menos essa aqui, mas tudo bem.

INQ.: Então... ou por exemplo você tá com muita sede, tá o que de sede?

INF.:Passando mal de sede, morrendo de sede, ah num...

INQ.: Deixa ...

Verifica-se que, durante a entrevista, o pesquisador utilizou alguns recursos para alcançar a resposta, porém, não esgotou as possibilidades do entrevistado. Nesse caso, optou-se por realizar uma retomada ao fim do questionário com as perguntas que não foram respondidas conforme o objetivo. É possível perceber que, nesse momento o pesquisador lançou mão de inúmeras estratégias e agiu insistentemente para alcançar o sucesso da questão que, mesmo assim, não se realizou.

Desse modo, fica evidente o comprometimento dos pesquisadores analisados no corpus desta pesquisa e seu papel fundamental para o sucesso da pesquisa que consolidou o Projeto ALiB.

\section{Considerações finais}

Pesquisas geolinguísticas envolvem acima de tudo pessoas, agentes da informação e investigadores desta informação. Um trabalho mais que complexo que exige planejamento, preparação e experimentação para quem se dispõe a desvendar esses caminhos. 
Com a presente pesquisa, buscou-se verificar as dificuldades do inquiridor na aplicação do questionário linguístico e seu papel nesse processo, principalmente diante das dificuldades de respostas do informante.

Cabe ressaltar que o questionário fonético exige uma lexia determinada, contudo, 0 item esperado pode não ser o modo usual da região, daquela faixa etária ou nível de instrução dos participantes, fator também este, possível causador das dificuldades de se alcançar o objetivo da questão analisada na presente pesquisa.

Diante dos dados, é possível verificar que, na maioria das entrevistas, foi necessária a intervenção do inquiridor. Observa-se que, apenas após o uso de reformulações, criação de novas situações ou de outros questionamentos é que se realiza o item desejado. Da mesma forma, fica constatado que a não insistência e a falta de intervenção adequada do inquiridor podem prejudicar o sucesso da coleta de dados.

Portanto, fica evidente o papel fundamental do inquiridor na busca de dados completos, reais e fidedignos e também a relevância da formação e preparo deste tipo de pesquisador, visto que os dados de um atlas não registram apenas fatos ligados à linguagem, mas podem também revelar a história, a vida, os costumes e a cultura do povo da região pesquisada.

\section{Referências}

ARAGÃO, Maria do Socorro Silvae. Avaliação dos procedimentos metodológicos nas entrevistas definitivas: os questionários. In: AGUILERA, Vanderci de Andrade; MOTA, Jacyra Andrade; MILANI, Gleidy Aparecida Lima (Org.). Documentos I: projeto atlas lingüístico do Brasil. Salvador: EDUFBA, 2003. p. 63-70.

CARDOSO, Susana Alice Marcelino; MOTA, Jacyra Andrade. Para uma nova divisão dos estudos dialetais brasileiros. In: . Documentos 2: projeto atlas linguístico do Brasil. Salvador: Quarteto, 2006. p. 15-26. 
CARDOSO, Suzana Alice Marcelino et al. (Org.). Documentos 4: projeto atlas linguístico do Brasil. Salvador: Vento Leste, 2013.

CARDOSO, Suzana Alice Marcelino. ALIB- Atlas Linguístico do Brasil: projeto. Salvador: UFBA, 1998.

COSERIU, Eugênio. A geografia linguística. In: El hombre y su

lenguaje. Tradução de Carlos A. da Fonseca e Mário Ferreira. Rio de Janeiro: Presença, 1987. p. 79-117.

FERREIRA, Carlota; CARDOSO Suzana Alice. A dialetologia no Brasil. São Paulo: Contexto, 1994.

MOUTON, Pilar García. Dialetologia y geografía lingüística. In: ALVAR, Manuel (Dir.). Manual de dialectología hispânica: el español de españa. Barcelona: Ariel, 1996. p. 63-77. 